\title{
Autonomia para gestão estratégica de pessoas no setor público federal: perspectivas de análise e agenda de pesquisa
}

\author{
Diogo Ribeiro da Fonseca \\ Universidade de Brasília \\ Pedro Paulo Murce Meneses \\ Universidade de Brasília \\ Antônio Isidro da Silva Filho \\ Universidade de Brasília \\ Natália Gomes Campos \\ Universidade de Brasília
}

\begin{abstract}
Este ensaio teórico tem por objetivo propor a autonomia como construto integrante de modelos estratégicos de gestão de pessoas em organizações públicas federais. O ambiente institucional, a estrutura e a cultura em organizações públicas podem oferecer restrições à autonomia de unidades de gestão de pessoas para o alinhamento de seus processos à estratégia organizacional. Nessa perspectiva, propõese a investigação de fatores ambientais de natureza formal e informal que condicionam as práticas de gestão de pessoas. Uma agenda de pesquisa é proposta visando a uma abordagem da gestão de pessoas mais adequada à realidade do setor público federal.
\end{abstract}

Palavras-chave: autonomia; descentralização; gestão estratégica; tomada de decisão; ambiente institucional.

Autonomía para gestión estratégica de personas en el sector público federal: perspectivas de análisis y agenda de investigación

Este ensayo teórico tiene como objetivo proponer la autonomía como constructo que integra los modelos estratégicos de gestión de personas en organizaciones públicas federales. El ambiente institucional, la estructura y la cultura en organizaciones públicas pueden ofrecer restricciones a la autonomía de unidades de gestión de personas para alinear sus procesos a la estrategia organizacional. En esa perspectiva, se propone la investigación de factores ambientales de naturaleza formal e informal que condicionan las prácticas de gestión de personas. Se propone una agenda de investigación dirigida a un abordaje de la gestión de personas más adecuado a la realidad del sector público federal.

Palabras clave: autonomía; descentralización; gestión estratégica; toma de decisiones; ambiente institucional.

Artigo recebido em 10 dez. 2012 e aceito em 4 set. 2013. 


\begin{abstract}
Autonomy for strategic human resource management in federal public sector: analytical perspectives and research agenda

This theoretical essay aims to propose autonomy as a construct that integrates strategic human resource management models in federal public organizations. The institutional environment, structure, and culture in public organizations may pose constraints to the autonomy of human resource departments to align their processes to the organizational strategy. From this perspective, we propose the investigation of environmental factors of formal and informal nature which affect human resource management practices. A research agenda is proposed aiming to provide a more adequate approach to the reality of human resource management in the federal public sector.
\end{abstract}

KEYWORDs: autonomy; decentralization; strategic human resource management; strategic decision making; institutional context.

\title{
1. Introdução
}

A administração pública, em diversos países, passou por reformas significativas a partir da década de 1980, tendo em vista a globalização dos mercados e a falência do modelo intervencionista de Estado, sujeito ao desequilíbrio fiscal e à ineficiência operacional em um cenário de crescente complexidade e competitividade (Bresser-Pereira, 1998). As reformas buscaram a modernização do setor público e a mudança do papel do Estado, que deixa de atuar diretamente na produção de bens e serviços para, então, desempenhar uma função de agente regulador e promotor do desenvolvimento econômico e social (Bresser-Pereira, 1998; Pacheco, 2002).

As reformas estatais empreendidas no Brasil seguiram, em muitos aspectos, as linhas do New Public Management (NPM) (Peci, Pieranti e Rodrigues, 2008) o qual estabelecia a perspectiva gerencialista como forma de superação do modelo burocrático. De tal perspectiva, práticas gerenciais da iniciativa privada foram adotadas como referência para transposição para o setor público, visando à geração de maior eficiência e foco em resultados (Bresser-Pereira, 1998; Peci, Pieranti e Rodrigues, 2008). Dentre as atividades que deveriam ser modernizadas encontra-se a gestão de recursos humanos (RH), até então voltada, no Governo como um todo, para sua função clássica de registro e controle de custos de funcionários (Pacheco, 2002).

Nesse contexto, iniciativa recente de mudança em políticas de gestão se expressa na edição do Decreto no 5.378/2005, que instituiu o Programa Nacional de Gestão Pública e Desburocratização (Gespública) (Brasil, 2005). No contexto da gestão de pessoas (GP), tal mudança se consubstanciou na edição do Decreto no 5.707/2006, que instaurou a Política Nacional de Desenvolvimento de Pessoal (PNDP) para os órgãos da administração direta, autárquica e fundacional. O normativo introduz a gestão por competências como instrumento de desenvolvimento contínuo dos servidores públicos e alinhamento de suas competências aos objetivos organizacionais (Brasil, 2006). A ênfase no desenvolvimento estratégico de servidores possibilita a relação da PNDP com as perspectivas teóricas de gestão estratégica de 
pessoas (GEP), as quais preveem o alinhamento dos processos de GP e das competências dos indivíduos à estratégia organizacional (Garavan, Costine e Heraty, 1995).

Não obstante as perspectivas de implantação de modelos estratégicos de GP na administração pública federal, há suficiente controvérsia na literatura acerca das implicações de sua transposição para esse contexto. O modelo de gestão por competências tem sua origem no setor privado britânico e norte-americano (Horton, 2000; OCDE, 2010b) de forma que, com base na literatura, podem ser suscitadas questões acerca da sua adaptação ao contexto brasileiro (Appel e Bitencourt, 2008; OCDE, 2010a; Wood Jr., Tonelli e Cooke, 2011), ao contexto específico do setor público (Ingraham e Rubaii-Barrett, 2007; Truss, 2003, 2008) e, por fim, acerca das lacunas teóricas, próprias de modelos estratégicos, sobre a viabilidade da adequação de processos de GP, a integração estratégica dessa atividade e sua expressão efetiva na prática organizacional (Brandl e Pohler, 2010; Gratton, 1999; Horwitz, 1999; Lacombe e Tonelli, 2001; Legge, 2005; Paauwe, 2004).

A abordagem estratégica de desenvolvimento de pessoas tem como pressuposto a existência de certa margem de decisão organizacional para a consideração de alternativas estratégicas para a adequação dos processos de GP aos objetivos da organização (Horwitz, 1999). No entanto, investigações empíricas têm demonstrado que fatores externos e internos à organização podem estabelecer restrições à margem de decisão gerencial, condicionando a adoção efetiva de modelos estratégicos pelas organizações (Lacombe e Tonelli, 2001; Paauwe, 2004; Paauwe e Boon, 2009; Brandl e Pohler, 2010) e sinalizando a necessidade de uma abordagem contingencial para a expressão de práticas de GEP (Horwitz, 1999).

Ao se considerar o ambiente específico do setor público, a transposição de práticas estratégicas gerenciais pode tornar-se ainda mais dificultada, tendo em vista que este se apresenta como um cenário normalmente mais restritivo do que aquele do setor privado (Ingraham e Rubaii-Barrett, 2007). O setor público caracteriza-se pela necessidade da harmonização de interesses de variados atores políticos e sociais, resultando em múltiplos objetivos alinhados a princípios de responsabilidade fiscal e social (Bach, 2010).

Visando à busca de coerência das práticas gerenciais em torno dos princípios e objetivos de governo, a administração pública é organizada como uma entidade integrada. De forma geral, sob o ponto de vista da gestão de pessoas, adota-se uma legislação transversal e coordenada por uma agência central de pessoal (ACP) voltada para o controle fiscal e gerencial da força de trabalho (Bach, 2010; Ingraham e Rubaii-Barrett, 2007). Dessa forma, tendo em vista que parte das políticas relevantes à gestão de pessoas é formulada e coordenada de maneira centralizada, o teor da legislação e dos controles definirá os parâmetros legais e a estratégia comum para orientação das organizações públicas na consecução dos objetivos de governo.

Segundo Peters (2008), a forma de atuação e controle das agências centrais pode ter como objetivo a condução indireta das atividades organizacionais, provendo certa margem de autonomia para o alcance de conformidade com políticas centralmente definidas, ou pode valerse de uma administração mais direta das decisões do dia a dia. Assim, com relação à gestão de pessoas, a forma de atuação governamental se situa entre uma função tradicional de controle procedimental e uma função de coordenação e planejamento (Hou et al., 2000). O modelo de 
atuação da ACP e os tipos de controles adotados definem, em cada atividade de gestão de pessoas, níveis de autonomia relativos à margem de decisão conferida às organizações públicas para adaptação de seus processos às suas estratégias específicas (Verhoest et al., 2004).

O alinhamento da força de trabalho aos objetivos organizacionais depende, portanto, da existência de níveis de autonomia que permitam a escolha pelas organizações de diferentes alternativas e modelos de desenvolvimento de pessoas que melhor atendam à sua estratégia. Adicionalmente, além dos condicionantes e parâmetros previstos em normativos gerais do setor público, as características específicas das organizações, como estrutura, estratégia, área de atuação e heranças culturais, podem definir internamente diferentes modelos de desenvolvimento de pessoas (Paauwe, 2004).

Poucos modelos teóricos abordam a influência de fatores contingenciais na transição e efetivação de um sistema estratégico de GP (Sheehan, 2005), no setor público os estudos específicos dessa linha ainda possuem um caráter exploratório e, em geral, são escassos (Bach, 2010; Truss, 2008). Tendo em vista essa lacuna teórica e a atestada necessidade de desenvolvimento de modelos de análise específicos aos contextos nacionais de administração pública, o presente trabalho tem como objetivo a apresentação de uma perspectiva de análise que enfatize a autonomia para implantação da gestão estratégica de pessoas em organizações públicas federais, tendo em consideração seu ambiente institucional específico. A tese subjacente desse ensaio é, com base em Paauwe (2004), de que a autonomia percebida pelos setores de gestão de pessoas para atuação em suas atividades condiciona o alinhamento de seus processos gerenciais às necessidades e à estratégia da organização. Nessa perspectiva, as restrições ambientais específicas do setor público federal são refletidas nessa percepção de autonomia, evidenciando os fatores relevantes que condicionam a adoção do modelo estratégico de gestão de pessoas, tal como previsto pelo Decreto no 5.707/06 e pela literatura em suas diversas vertentes e abordagens.

Para desenvolvimento do percurso teórico do presente ensaio são apresentadas, primeiramente, as bases teóricas da gestão por competências como modelo estratégico de gestão de pessoas, as diferentes perspectivas teóricas de integração estratégica do setor de GP e uma perspectiva de análise que leve em consideração os fatores ambientais condicionantes para implantação de modelos estratégicos. Seguidamente, aspectos específicos ao ambiente do setor público são apresentados, sendo propostas definições constitutivas e operacionais do conceito de autonomia visando subsidiar os estudos nessa área. Para tanto, alguns estudos atuais são destacados e uma agenda de pesquisa é proposta.

\section{Abordagem estratégica de gestão de pessoas}

A abordagem estratégica de gestão de pessoas se delineou a partir da década de 1980, com o crescente reconhecimento da importância do capital humano na consecução de estratégias organizacionais, considerando-o uma vantagem competitiva (Lacombe e Tonelli, 2001). O modelo de gestão por competências se insere no contexto da GEP dado que se caracteriza pelo alinhamento horizontal, das atividades de gestão de pessoas, e vertical, dessas atividades com a estratégia da organização (figura 1) (OCDE, 2010b). 
Figura 1

Alinhamento vertical e horizontal das atividades de gestão de pessoas

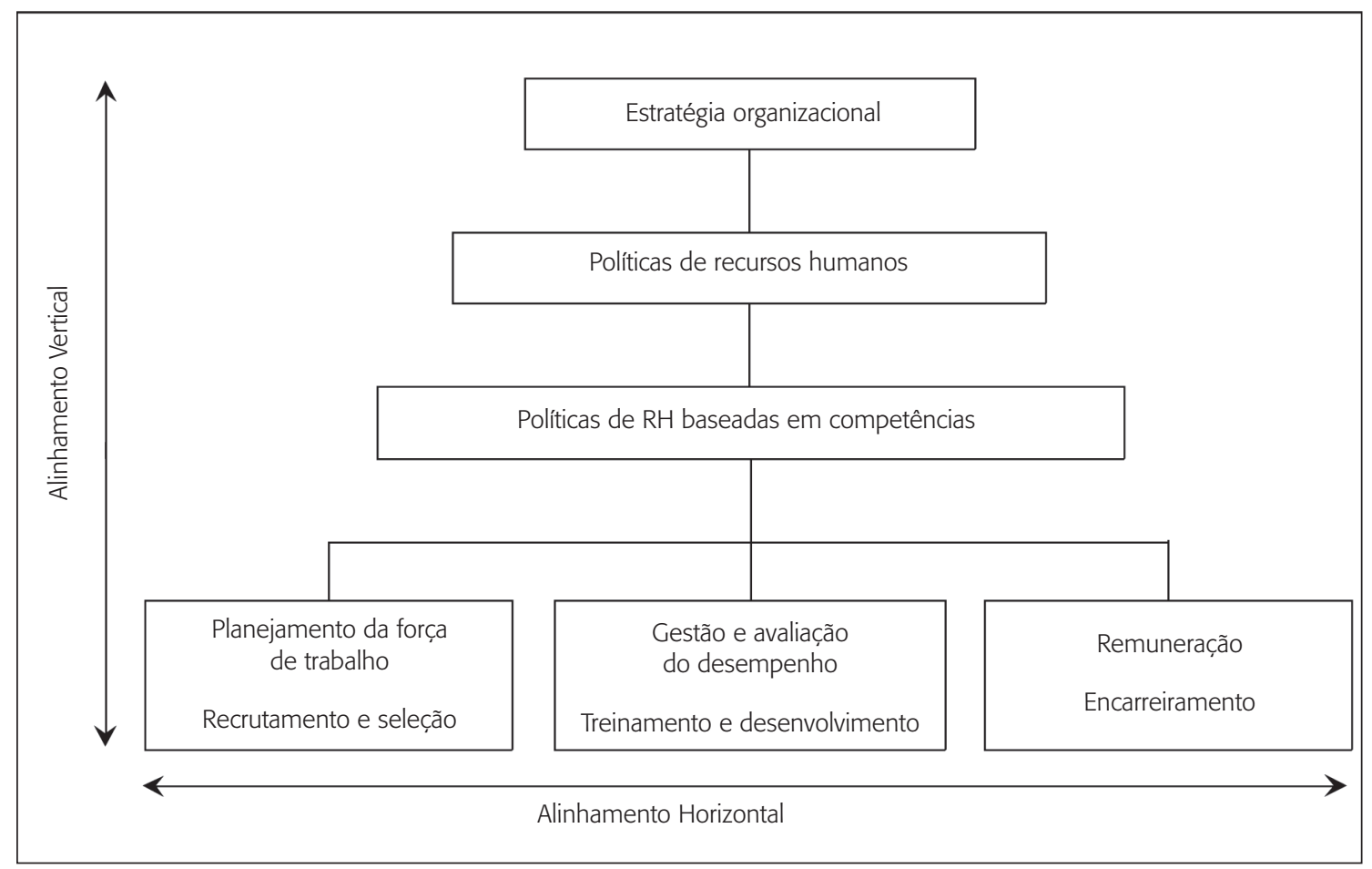

Fonte: Van Beirendonck (2009) apud OCDE (2010b), tradução nossa.

Sob o ponto de vista do alinhamento vertical, a estratégia organizacional subsidia a definição de competências organizacionais, as quais são desdobradas em competências individuais expressas em requisitos de atributos cognitivos (conhecimentos e habilidades) e comportamentais (atitudes) para o desempenho do trabalho na organização (OCDE, 2010b; Brandão e Guimarães, 2001). Nesse sentido, a gestão por competências seria efetivada por uma política de gestão de pessoas voltada para o gerenciamento da lacuna de competências individuais, buscando a redução do déficit entre as competências necessárias à consecução dos objetivos organizacionais e aquelas já disponíveis na organização (Brandão e Bahry, 2005; Brandão e Guimarães, 2001). Para viabilizar o alinhamento horizontal, a definição de competências serve de parâmetro comum aos diferentes sistemas de GP, permitindo sua conexão (OCDE, 2010a, 2010b).

O processo de transição para um modelo estratégico de gestão de pessoas não é claramente abordado nas teorias clássicas de GP (Paauwe, 2004; Sheehan, 2005). Diversos são os autores que, de diferentes perspectivas, indicaram condicionantes de natureza formal para esse processo de transição como: estrutura, função e estratégia da organização, características da força de trabalho e ambiente legal trabalhista (e.g., Datta, Guthrie e Wright, 2005; De Pablos, 2004; Farndale et al., 2010; McCracken e Wallace, 2000; Muller, 1999; Muritiba et al., 2010), 
até aqueles de natureza mais informal, a exemplo das culturas nacionais de trabalho e organizacionais, as redes sociais informais e as percepções de atores organizacionais (e.g., Brandl e Pohler, 2010; Ferner et al., 2004; Gooderham, Nordhaug e Ringdal, 1999; Truss, 2003, 2008).

Tal lacuna teórica se deve, em parte, ao pressuposto da racionalidade que prevalece nas teorias de gestão estratégica de pessoas (Legge, 2005). Por exemplo, considera-se que o principal fator de análise que caracteriza a existência da GEP refere-se à inserção dessa atividade e de seu setor na elaboração da estratégia da organização (McCracken e Wallace, 2000; Garavan, Costine e Heraty, 1995; Golden e Ramanujam, 1985 apud Paauwe e Boon, 2009; Gratton, 1999; Wright e Snell, 1998). Sob essa linha, o planejamento estratégico é considerado uma das principais referências para a definição de competências organizacionais e individuais (Brandão e Bahry, 2005; OCDE, 2010a). No entanto, estudos sobre a adoção da GEP em diversas organizações demonstram que tal perspectiva racional não é assumida de forma direta, inequívoca, nem frequente nas organizações (Brewster, Larsen e Mayrhofer, 2000; Legge, 2005; Torraco e Swanson, 1995). Em razão dos pressupostos nos quais se baseiam, as teorias de GEP não constatam a natureza complexa e multidimensional do processo de elaboração estratégica, no qual elementos informais da organização permitem o alinhamento estratégico da gestão de pessoas sob variadas formas afora o planejamento formal (Brewster, Larsen e Mayrhofer, 2000; Paauwe, 2004; Torraco e Swanson, 1995).

Como evidência da relevância de tais fatores informais, se verifica que, na maior parte das vezes, a iniciativa de inserção do setor de gestão de pessoas no processo de formulação estratégica parte do próprio gestor da unidade, numa perspectiva de negociação (Truss, 2003), de integração política (Brewster, Larsen e Mayrhofer, 2000; Drory e Vigoda-Gadot, 2010) e de construção da reputação e legitimidade do setor junto a atores-chave da organização (Brandl e Pohler, 2010; Ferris et al., 2007). Dessa forma, conforme Legge (2005), Brewster, Larsen e Mayrhofer (2000) e Paauwe e Boon (2009), é necessária uma ampliação da concepção de estratégia para além do modelo racionalista clássico para que sejam consideradas diferentes dimensões de integração da atividade de gestão de pessoas ao processo de elaboração estratégica da organização.

\subsection{Perspectivas sobre o processo de elaboração estratégica}

A literatura apresenta diferentes concepções de estratégia que variam de duas perspectivas, uma de que o processo estratégico é racional, deliberado e planejado e outra de que esse processo é emergente, iterativo e focado na flexibilidade e competitividade organizacional para adequação imediata à dinâmica do ambiente (Legge, 2005; Paauwe, 2004; Paauwe e Boon, 2009; Wright e Snell, 1998). A abordagem formal-sinóptica, ligada à perspectiva racional clássica (Brewster, Larsen e Mayrhofer, 2000), assevera que as estratégias são fruto de um processo de planejamento. Essa abordagem dispõe de uma série de pressupostos, entre os quais o de que a fase de planejamento e elaboração da estratégia é distinta e separada funcionalmente da etapa de implementação, cabendo às unidades de planejamento estratégico da organização supervisionar sua implementação pelas demais unidades de execução. As implicações desse modelo são de que há uma dependência dos níveis inferiores em relação aos 
níveis superiores, de forma que a estratégia de gestão de pessoas decorrerá do desdobramento da estratégia organizacional (Legge, 2005).

Em oposição à abordagem formal-sinóptica, aquela denominada de abordagem informalincremental (Brewster, Larsen e Mayrhofer, 2000) focaliza os elementos emergentes durante a implantação da estratégia organizacional. Um primeiro pressuposto é de que não é verossímil que um processo estratégico formal e previamente deliberado se concretize exatamente como foi concebido na prática, não somente em função da racionalidade limitada dos atores, como também da dinâmica instável do ambiente organizacional externo e interno (Paauwe, 2004). Nessa perspectiva, a estratégia é um processo emergente formado pelo conjunto difuso de interesses de diversos stakeholders, internos e externos, além das influências oriundas da dinâmica do ambiente organizacional (Paauwe, 2004). A estratégia é suscetível, portanto, a elementos simbólicos e políticos, como a cultura organizacional, os processos de negociação e a estrutura informal. Nesse sentido, a participação no processo de elaboração da estratégia pode ocorrer de forma direta ou indireta, envolvendo, respectivamente, a participação de membros e gestores do setor de GP no processo estratégico formal, ou por meio da influência sobre os atores-chave no processo decisório da organização (Brewster, Larsen e Mayrhofer, 2000). O quadro 1 elucida as características-chave de cada uma das abordagens antes expostas.

Quadro 1

\section{Conceituações básicas de estratégia e gestão estratégica}

\begin{tabular}{|lll|}
\hline CARACTERÍSTICAS-CHAVE & \multicolumn{1}{c}{ ABORDAGEM FORMAL-SINÓPTICA } & ABORDAGEM INFORMAL-INCREMENTAL \\
\hline Modelo de Organização & Ator racional & Sistema sociopolítico, coalizões, garbage can \\
Conceito de Estratégia & $\begin{array}{l}\text { Plano deliberadamente formulado destinado } \\
\text { à realização }\end{array}$ & Padrão interpretado de decisão e ação \\
Escopo de Ação & Planejamento abrangente & Ação sobre problema singular e importante \\
Tomada de Decisão & Processo de planejamento formal & Informal \\
Autoridade Decisória & Alta administração & Descentralizado \\
Processo Decisório & Processo sinóptico de etapas de & Processo iterativo com várias \\
Fases de Decisão & planejamento & retroalimentações \\
& Divisão sequencial de formulação e & Sem divisões; estratégia se desenvolve \\
implementação da estratégia & incrementalmente e se torna visível na sua \\
Gerenciamento das & Operacionalização do plano estratégico por & Gerenciamento simbólico e cultural, \\
Estratégias & meio da estrutura organizacional e de liderança & ideologias, visões e quadro geral \\
\hline
\end{tabular}

Fonte: Brewster, Larsen e Mayrhofer (2000), tradução nossa.

Como demonstrado por Legge (2005), a principal questão levantada, portanto, se refere à relevância da participação formal do setor de GP na elaboração estratégica, uma vez que não se pode assumir que as fases formais de planejamento e elaboração estratégica representam o único ponto de influência nesse processo. A influência dos setores de GP pode ocorrer informalmente, exibindo uma falta de articulação formal de estratégias de GP com 
a estratégia organizacional, porém embutindo-as de forma implícita nas decisões cotidianas (Legge, 2005), tendo em vista que parte das decisões estratégicas reais tem um caráter informal (Brewster, Larsen e Mayrhofer, 2000). Dessa forma, a GEP, ao se fundamentar tanto em decisões formais quanto emergentes, não deve ser reduzida à vinculação de suas políticas ao planejamento e objetivos organizacionais, mas deve também responder a outros aspectos do processo global de formulação estratégica, a exemplo dos processos decisórios informais e emergentes que influenciam as demandas submetidas à área.

As perspectivas formal e informal de inserção da unidade de gestão de pessoas no processo de elaboração estratégica da organização definem diferentes formas de atuação. A participação direta do setor na formulação e na implementação da estratégia organizacional caracteriza o modelo clássico de decisão em que este figura como especialista, podendo atuar como um provedor de informações e serviços necessários à consecução da estratégia. As informações são fornecidas no sentido de que possam legar impacto à estratégia organizacional e, consequentemente, adequar políticas e práticas de GP (Garavan, Costine e Heraty, 1995; McCraken e Wallace, 2000).

Apesar da importância dada pela teoria à participação direta do setor de gestão de pessoas no processo de elaboração estratégica, seu envolvimento nas arenas informais de tomada de decisão também parece ser crucial. A consideração do setor de GP como atividade relevante no cotidiano organizacional permite sua participação informal no processo de execução estratégica, sob um aspecto consultivo ou colaborativo, sem a necessidade de sua explicitação em documentos ou processos decisórios formais (Brewster, Larsen e Mayrhofer, 2000; Sheehan, 2005).

A revelação da dimensão informal da participação estratégica da função de GP, principalmente por estudos empíricos na área, demonstra o poder dos processos políticos e culturais da organização, que vão além da dimensão formal das decisões (Brandl e Pohler, 2010; Legge, 2005; Sheehan, 2005; Truss, 2003, 2008). Com base nos avanços desse campo e integrando perspectivas da teoria institucional, abordagem contingencial, teoria baseada em recursos e a abordagem configuracional (Paauwe e Boon, 2009), Paauwe (2004) propõe um modelo abrangente que busca considerar os possíveis fatores ambientais intervenientes na implantação e formatação de um modelo de GEP.

\subsection{Teoria contextualmente fundamentada de gestão de pessoas}

A síntese de Paauwe (2004) dos modelos existentes se apresenta como uma abordagem sistêmica na qual os aspectos internos e externos, formais e informais são refletidos no conteúdo e nos resultados das políticas e práticas de GP, condicionando sua efetiva vinculação estratégica. Nesse modelo, as influências externas se agrupam em duas dimensões: Produto/ Mercado/Tecnologia, que reflete o ambiente competitivo (ambiente técnico) da organização, e a dimensão Social/Cultural/Legal, que se refere ao ambiente institucional de conformidade e legitimação do sistema de GP. Enquanto a dimensão técnica exige critérios de eficiência, 
qualidade, flexibilidade, agilidade e inovação visando à competitividade organizacional, a dimensão institucional impõe padrões e modelos de atuação sob um ponto de vista relacional simbólico com stakeholders. Além dessas, uma terceira dimensão é enfatizada nesse modelo, de natureza interna, qual seja, a Cultural/Histórica/Administrativa organizacionais, que legam uma configuração única à organização e à forma e expressão do sistema de GEP.

Paauwe (2004) apresenta as três dimensões ambientais como grupos de fatores que concorrem por determinar o espaço ou a liberdade possuídos pela organização para a tomada de decisões estratégicas. Para o autor, os atores-chave da organização é que possuem a prerrogativa de determinação das práticas de GP, implicando nesses a cúpula organizacional, os conselhos deliberativos e, em alguns casos, o gestor de RH. A composição dessa coalizão dominante não é necessariamente formal, e ocorre em razão de uma miríade de fatores que refletem a dinâmica política organizacional (Paauwe, 2004). Nessa perspectiva, o processo decisório em GP é dinâmico e pluralista, ao considerar os interesses e a influência de diferentes stakeholders e restrições ambientais. A capacidade de manobrar os sistemas de GP para atendimento de interesses estratégicos depende da natureza e da coercitividade das influências externas e internas. A representação do modelo com indicação das diversas influências ambientais na organização é exibida na figura 2 .

Figura 2

Teoria contextualmente fundamentada de recursos humanos

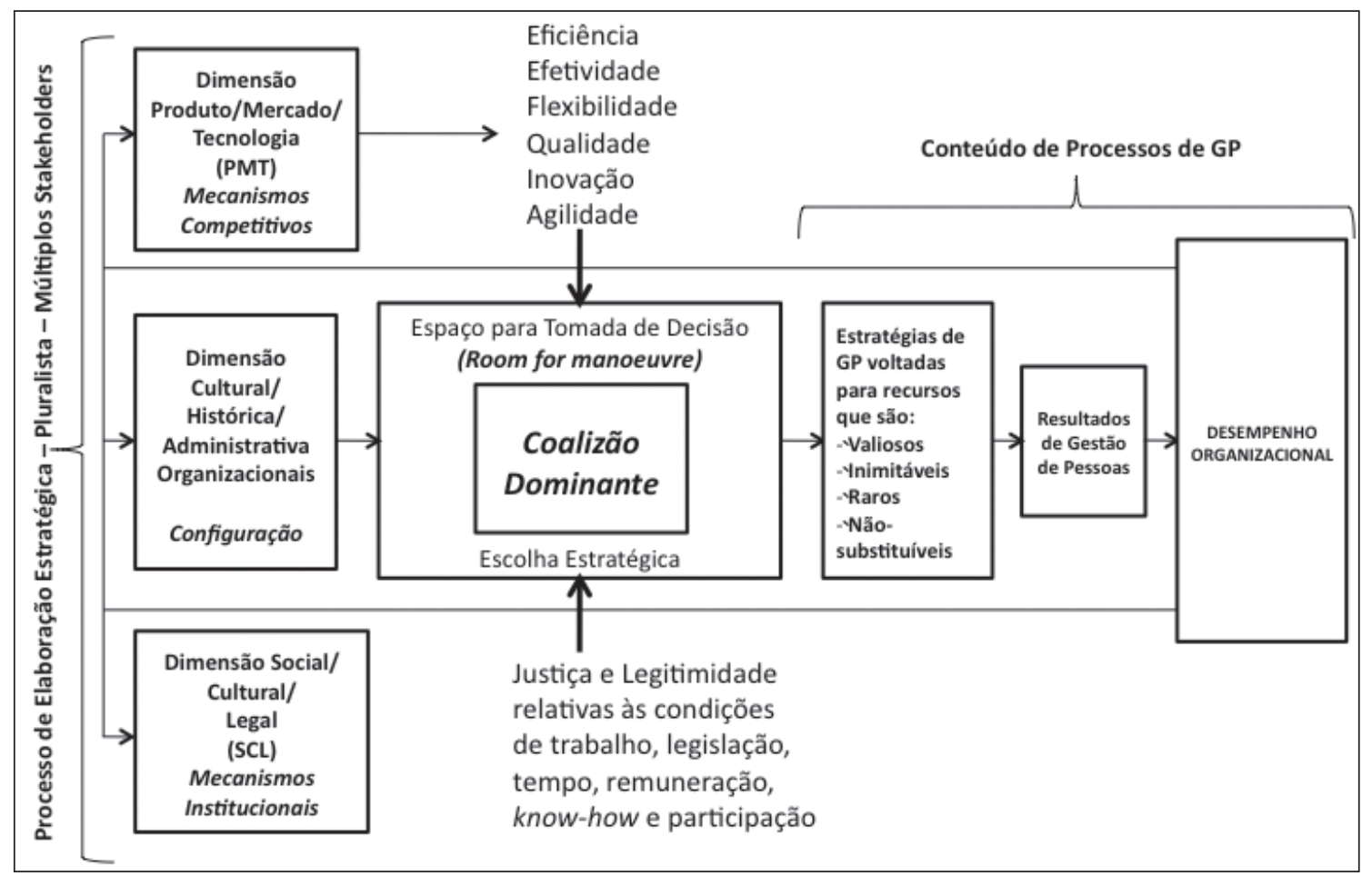

Fonte: Paauwe (2004), tradução nossa. 
Paauwe (2004) e Paauwe e Boon (2009) alertam para o fato de que é possível que os modelos teóricos de GP, conforme postulados na literatura, podem, em muitas organizações, jamais ser implementados em razão das restrições de seus ambientes. Em acordo com Wright e Snell (1998) e Torraco e Swanson (1995), os autores explicam que condições de mercado, exigências ambientais específicas e o próprio ambiente organizacional podem levar a organização a adotar conscientemente modelos mais simples e tradicionais de GP. O exame dos fatores ambientais serve de subsídio para análise das implicações da adaptação de modelos estratégicos de GP, conforme postulados na literatura, ao contexto específico do setor público. Com o propósito de construir modelos teóricos adequados a essa realidade, alguns estudiosos analisaram os fatores específicos que afetam o desenvolvimento da GEP em organizações públicas.

\section{Fatores de implantação da gestão estratégica de pessoas no setor público}

A transição do setor de GP para uma função estratégica em organizações públicas foi analisada por Truss $(2003,2008)$, que realizou estudos em diferentes setores no serviço público britânico. Sob uma perspectiva informal, a autora atesta a importância fundamental da atuação do gestor de RH no ambiente político da organização por meio da negociação do poder sobre as decisões de GP e a gradual transição para um modelo estratégico. Outro fator que reflete essa atuação política é a mudança das percepções e expectativas dos atores organizacionais em relação ao papel do setor, legitimando-o (Ferris et al., 2007). Truss (2008) observa, nas organizações que visitou, que: "Era, portanto, evidente que o grau de transição não era específico do setor, mas dependia muito das ações e intenções dos atores organizacionais, em especial o gestor ou diretor de $\mathrm{RH}$, bem como do contexto organizacional vigente" (Truss, 2008:1084, tradução nossa).

Do ponto de vista teórico, essas questões haviam sido apontadas por Sheehan (2005) e Brandl e Pohler (2010), por exemplo, ao demonstrar que a legitimação da área perante os gerentes de linha e a cúpula é responsável pela maior inserção estratégica das atividades de GP em empresas privadas. Apesar da convergência de resultados entre esses estudos, segundo Truss (2008), além de fatores políticos do ambiente organizacional, parte da decisão de implementação da abordagem estratégica se deveu à pressão formal do governo central, por meio das agências centrais de pessoal de cada setor analisado. Assim, havia uma infraestrutura normativa, externamente definida, que incentivava a adoção de uma perspectiva estratégica, porém dentro dos moldes estabelecidos pelo governo. Desta forma, uma das características distintivas do setor público é a existência de ACPs que possuem a prerrogativa de delimitar centralmente o conteúdo das práticas de gestão de pessoas (Hou et al., 2000).

Em geral, na administração pública, a estratégia de gestão de pessoas é estabelecida de forma centralizada, cabendo às organizações mobilizar-se internamente para se adaptarem ao ambiente. Um cenário de maior centralização e controle, o qual remete ao paradigma burocrático de gestão pública, em teoria, obsta a autonomia estratégica dos órgãos que absorvem, 
por força institucional, a estratégia e o modelo de gestão definidos pelo governo. Assim, as condições ambientais que podem limitar a implantação da GEP em organizações públicas ocorrem, segundo Truss (2008), principalmente em razão das restrições externas impostas pela centralização normativa de práticas de gestão de pessoas:

A continuidade do domínio de imperativos do Governo Central sobre todas as organizações públicas através de auditoria e definição de metas, em combinação com o controle central sobre práticas e recursos, define os limites da discricionariedade administrativa e o grau de escolha estratégica disponível para atores do RH dentro das organizações públicas. (Truss, 2008:1073, tradução nossa)

Para Ingraham e Rubaii-Barrett (2007), a cultura funcional nas relações de trabalho, a estrutura burocrática, a rigidez dos processos e a falta de um perfil de liderança do setor de GP são dificuldades inerentes ao serviço público. Em geral, essas dificuldades referem-se a estruturas que não estão, em sua maior parte, sob a jurisdição das organizações para que sejam alteradas. Dentro de uma perspectiva de interferência política e normativa, as autoras ainda apontam como fator negativo a estrutura de indicação de cargos, que promove a entrada de gestores ligados a interesses políticos e promovem rupturas na consistência estratégica da organização, por não estarem familiarizados com sua trajetória e objetivos estratégicos (Ingraham e Rubaii-Barrett, 2007). Assim, diferentemente do setor privado, além do apoio da cúpula organizacional e gestores de linha, amplamente referenciado na literatura, em se tratando do setor público, o apoio e as políticas do governo central condicionam a implantação de GEP nesse âmbito (Truss, 2008).

Tendo como referência a administração pública federal no Brasil, atesta-se que há nesse contexto um forte grau de centralização administrativa (OCDE, 2010a; Peters, 2008). Uma das principais contingências formais do setor público brasileiro, a Constituição de 1988 (Brasil, 1988), promoveu a centralização normativa da gestão pública e a maior ênfase nos controles estatais como resposta à crise política e fiscal delineada na década de 1980 (Bresser-Pereira, 1998). Na área de gestão de pessoas, essa iniciativa se consubstanciou com a edição do Regime Jurídico Único (RJU), estendido a toda a administração pública. Esse dispositivo, em alguns aspectos, aprofundou o corporativismo e a rigidez das políticas de gestão de pessoas (Bresser-Pereira, 1998).

Tendo em vista o aspecto estrutural de organização e delegação de poder decisório no âmbito do setor público, a existência de graus de descentralização e autonomia organizacional deve ser analisada como possível condicionante à expressão de modelos estratégicos de gestão de pessoas. Parte desse referencial, oriundo da literatura de administração pública, serve de base para a compreensão da formação do "espaço de manobra", tal como descrito por Paauwe (2004), como variável que, segundo o autor, condiciona a implantação da GEP nas organizações. Tais aspectos contingenciais do processo decisório, citados sob variadas denominações nos estudos elencados, podem ser analisados da perspectiva do construto da autonomia. 


\section{Descentralização e dimensões de autonomia no setor público}

A temática da descentralização tem sido uma questão central no debate acerca do papel e da organização do Estado, porém ainda é considerada pouco consolidada na literatura até a atualidade (Vieira, 2012). Tal debate ocorre em função das reformas estatais empreendidas recentemente, motivadas por crises políticas e econômicas que põem em discussão novos modelos de governança pública e estratégias de desenvolvimento em diversos países (Peters, 2008; Peci, Pieranti e Rodrigues, 2008).

O conceito de autonomia, por sua vez, tem maior afluência dentro do ideário do New Public Management (Smullen, 2003), que caracterizou as reformas estatais empreendidas na década de 1990 no Brasil, por exemplo. Nesse âmbito, a prescrição de maior autonomia se alia à ideologia gerencialista, como forma de se fornecer maior margem de decisão aos gestores públicos para adoção de práticas da iniciativa privada, aliada à maior capacidade de responsabilização desses gestores e controle de suas atividades por metas e resultados (Bresser-Pereira, 1998; Smullen, 2003; Peci, Pieranti e Rodrigues, 2008; Peters, 2008).

Nessa perspectiva, no setor público a descentralização é formal e geradora de autonomia potencial, ao transferir o poder decisório de uma unidade central para unidades subordinadas (Vieira, 2012). Como contrapartidas de maior delegação de autoridade, são estabelecidas diferentes formas de controle e monitoramento das atividades organizacionais, visando seu alinhamento aos objetivos e diretrizes de governo (Verhoest et al., 2004). A maior descentralização concede autoridade formal sobre atividades organizacionais (Young e Tavares, 2004), porém o grau de autonomia auferido pela organização depende da natureza e da força dos controles criados como contrapartida da descentralização (Verhoest et al., 2004).

Segundo a literatura, há, portanto, dois tipos de autonomia: 1) autonomia como competência decisória, ou autoridade formal e 2) autonomia como o exercício efetivo dessa competência, em face de controles e restrições ambientais (Verhoest et al., 2004). Young e Tavares (2004) se referem a essas como autonomia formal e informal. Braadbaart, Van Eybergen e Hoffer (2007) realizam a mesma distinção, estabelecendo uma diferença entre autonomia como previsto na lei e autonomia no dia a dia das atividades organizacionais, o que se pode chamar de autonomia de jure (formal, conforme a lei) e autonomia de facto (real) (Yesilkagit e Van Thiel, 2008).

A categorização dos controles e das restrições ambientais como formais e informais visa à análise discriminada dos fatores relevantes para a capacidade de decisão e atuação de gestores no setor público. No que tange ao aspecto objetivo e formal, as burocracias clássicas tendem a realizar uma restrição do ponto de vista da regulação ex ante dos atos, isto é, elaboram-se regulamentos prévios que devem orientar a ação organizacional, bastando ao gestor público cumprir rigorosamente as diretrizes centrais (Verhoest et al., 2004). Maior autonomia formal se daria com a diminuição dos controles ex ante, com maior discricionariedade do gestor para tomar decisões. Em Verhoest e colaboradores (2004), a competência decisória formal dos gestores refere-se a duas dimensões: a gerencial (managerial 
autonomy), referente à gestão dos inputs necessários a suas atividades e que se expressam geralmente em recursos financeiros, humanos e logísticos; e a de formulação e execução de políticas (policy autonomy), referente à liberdade para tomar decisões em sua área de atuação e definir objetivos, processos de trabalho, instrumentos, produtos (quantidade e qualidade) e público-alvo.

O aspecto informal da autonomia refere-se a quanto o gestor está sujeito a restrições em seu poder decisório original. Conforme Verhoest e colaboradores (2004), controles e interferências dessa natureza podem ser realizados por meio da atuação governamental, tendo como exemplos: a indicação política de gestores que são incumbidos de representar os interesses de outros stakeholders; a restrição à autonomia financeira da organização por meio de cortes e contingenciamentos orçamentários; a modificação ou supressão de leis que garantam proteção à atuação do gestor; e, por fim, a utilização de supervisão, punições, auditorias e demais meios que possam condicionar a ação gerencial pelo risco de controles ex post.

Tanto os aspectos formais e informais citados correspondem à dimensão institucional, proposta por Paauwe (2004), na qual são considerados os aspectos coercitivos e normativos do ambiente. Nessa dimensão, a análise recai sobre a relação das organizações públicas com o governo e sua autonomia para execução de políticas públicas. No entanto, conforme as citadas perspectivas de análise da literatura de GP, as unidades responsáveis por esta atividade estão sujeitas também a fatores referentes ao ambiente interno da organização, a qual caracteriza sua dimensão administrativa, cultural e histórica (Paauwe, 2004). Nesse sentido, é necessária a ampliação das concepções de autonomia formal e informal para esse nível de análise, como forma de se definir a margem de decisão adequada a um modelo estratégico de gestão de pessoas.

\subsection{Descentralização organizacional e autonomia de unidades de gestão de pessoas}

Ao considerar o nível organizacional de análise, para Brock (2003), a descentralização é responsável pela distribuição formal de poder decisório, sendo definida em termos de lócus de tomada de decisão. Decisões centralizadas implicam sua restrição à unidade deliberativa superior do sistema organizacional, enquanto a descentralização implica a concessão do poder decisório às unidades subordinadas, em termos de participação ou delegação de autoridade.

A autonomia dos gestores no ambiente organizacional, por sua vez, se define pelo escopo e quantidade de decisões que podem ser tomadas por estes, sem a participação ou interferência de outros atores (Brock, 2003). A descentralização fornece a estrutura para exercício da decisão, enquanto a autonomia reflete a capacidade do gestor de realizá-las de fato (Brock, 2003). O quadro 2 apresenta a distinção entre os termos tratados no âmbito da estrutura organizacional. 
Quadro 2

Definições típicas e operacionalizações de centralização e autonomia

\begin{tabular}{|lll|}
\hline \multicolumn{1}{|c|}{ Variável } & \multicolumn{1}{c|}{ Definição } & \multicolumn{1}{c|}{ Operacionalização } \\
\hline $\begin{array}{l}\text { Autonomia } \\
\text { (de atores organizacionais) }\end{array}$ & $\begin{array}{l}\text { Extensão da autoridade sobre decisões } \\
\text { (quantas decisões) }\end{array}$ & $\begin{array}{l}\text { Quantas decisões podem ser tomadas sem } \\
\text { participação superior }\end{array}$ \\
$\begin{array}{l}\text { Centralização } \\
\text { (da estrutura) }\end{array}$ & $\begin{array}{l}\text { Lócus da decisão } \\
\text { (onde é realizada) }\end{array}$ & $\begin{array}{l}\text { Qual o nível mais baixo da organização a tomar } \\
\text { a decisão }\end{array}$ \\
\hline
\end{tabular}

Fonte: Brock (2003), tradução nossa.

Com base na apropriação proposta dos conceitos de autonomia formal e informal, a autonomia real de unidades de gestão de pessoas está sujeita aos controles e às interferências formais e informais existentes no ambiente interno da organização. Portanto, de forma agregada, estabelecem-se pelo menos três momentos para análise da formação da autonomia, os quais implicam diferentes controles e fatores associados. Em um primeiro momento, existe a delegação do governo central para as organizações públicas, em que são definidos os parâmetros e o escopo de atividades dentro dos quais se podem tomar decisões autônomas. Posteriormente, há a delegação dessas atividades a partir das instâncias decisórias máximas da organização para as unidades subordinadas. Logo, em seguida, ocorre o exercício efetivo da competência decisória prevista, em face dos diversos fatores condicionantes de diversas naturezas: legais, estruturais, culturais, políticos e recursos disponíveis. Essa análise implica que a autonomia é, portanto, relativa (Young e Tavares, 2004), quando se insere dentro de um escopo potencial de ação, normalmente delegada por um ator central. Nesse sentido, cabe à cúpula organizacional delegar ao setor de GP a autonomia formal sobre as decisões descentralizadas pelo governo. Mediante a abstenção tanto por parte do governo quanto dos atores organizacionais de interferir no setor de GP, este passa a gozar de autonomia real para influenciar seus próprios processos e resultados. Assim, a figura 3 apresenta um modelo conceitual sugerido para a construção da autonomia no setor público, no qual essa resulta de um processo de transferência de poder, cujo exercício efetivo está sujeito a contingências do ambiente organizacional (Paauwe e Boon, 2009).

Dessa forma, a autonomia resultante de um processo de descentralização é condicionada pelos controles formais e informais que são exercidos sobre o gestor em sua tomada de decisão. Pode ser depreendido um continuum entre autonomia e controle no ambiente institucional do setor público (Verhoest et al., 2004) e, mesmo em um contexto de maior descentralização, restrições do ambiente interno da organização podem afetar a implantação da GEP (Paauwe, 2004). 
Figura 3

Processo simplificado de formação da autonomia no setor público

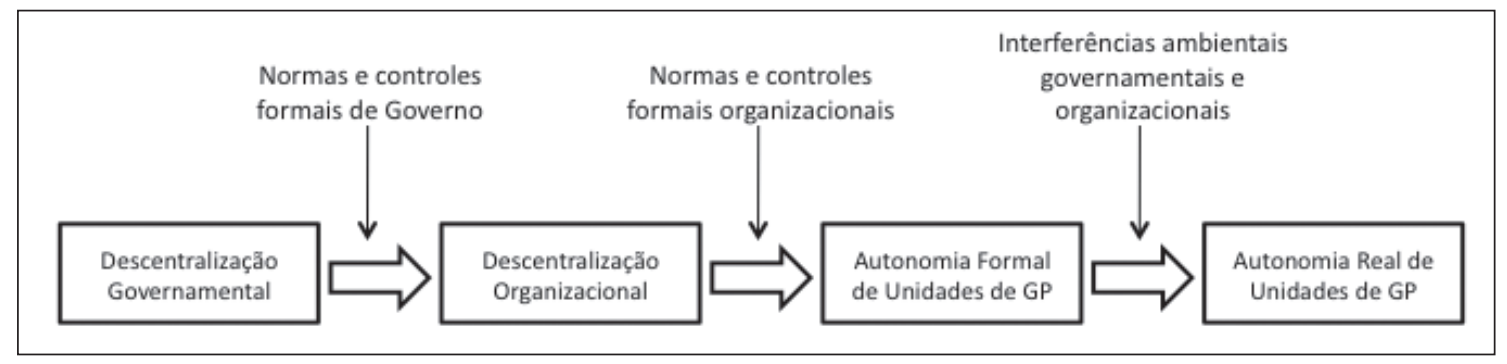

Fonte: Elaboração própria.

\section{Perspectivas propostas para análise da autonomia de unidades de gestão de pessoas no setor público}

A autonomia de unidades de gestão de pessoas é influenciada por diversos fatores institucionais e organizacionais até que se expresse no teor das decisões do gestor de RH, ou da coalizão dominante, ao se considerarem decisões estratégicas (Paauwe e Boon, 2009). Para alguns autores, a autonomia, apesar de decorrer do conjunto de controles formais e informais existentes, se expressa, de fato, por meio da autonomia percebida pelos gestores, a qual interfere em seu exercício efetivo. Ao operacionalizar o construto no ambiente de trabalho, autores detectaram que os decisores-chave da organização concebem, conforme sua interpretação das contingências ambientais e de suas características individuais, qual sua real autonomia para mudanças das atividades de GP (Brandl e Pohler, 2010; Truss, 2008). Nesse nível perceptual, aspectos como o domínio de informações, conhecimento sobre os recursos disponíveis, assim como a posição do gestor na estrutura organizacional são considerados em seu processo decisório (Brandl e Pohler, 2010).

Nesse sentido, a mensuração da autonomia é perceptual, tendo em vista a impossibilidade de se conceber a totalidade de fatores que a defina. $\mathrm{O}$ efeito de maior ou menor autonomia só se concretiza quando o tomador de decisão percebe sua margem e oportunidade de atuação (Brandl e Pohler, 2010). Assim, a percepção de autonomia dos indivíduos define as ações do setor de GP, demonstrando o aspecto subjetivo do escopo de ação do setor. Essa importante constatação da realidade organizacional acrescenta para as análises de autonomia a compreensão de que esta não é apenas atribuída pelo governo central à organização, mas ela também pode ser construída e modificada pela organização por meio de um processo de construção social e modificação de seu ambiente (Young e Tavares, 2004). Consolidando as perspectivas das literaturas de GEP e autonomia no setor público, apresenta-se uma adaptação de parte do modelo de análise de Paauwe (2004) (figura 4), que visa esboçar a dinâmica entre ambiente e autonomia no setor público para a adoção de modelos estratégicos de GP e sua execução efetiva. 
Figura 4

\section{Representação de influências ambientais na implantação da gestão estratégica de pessoas no serviço público}

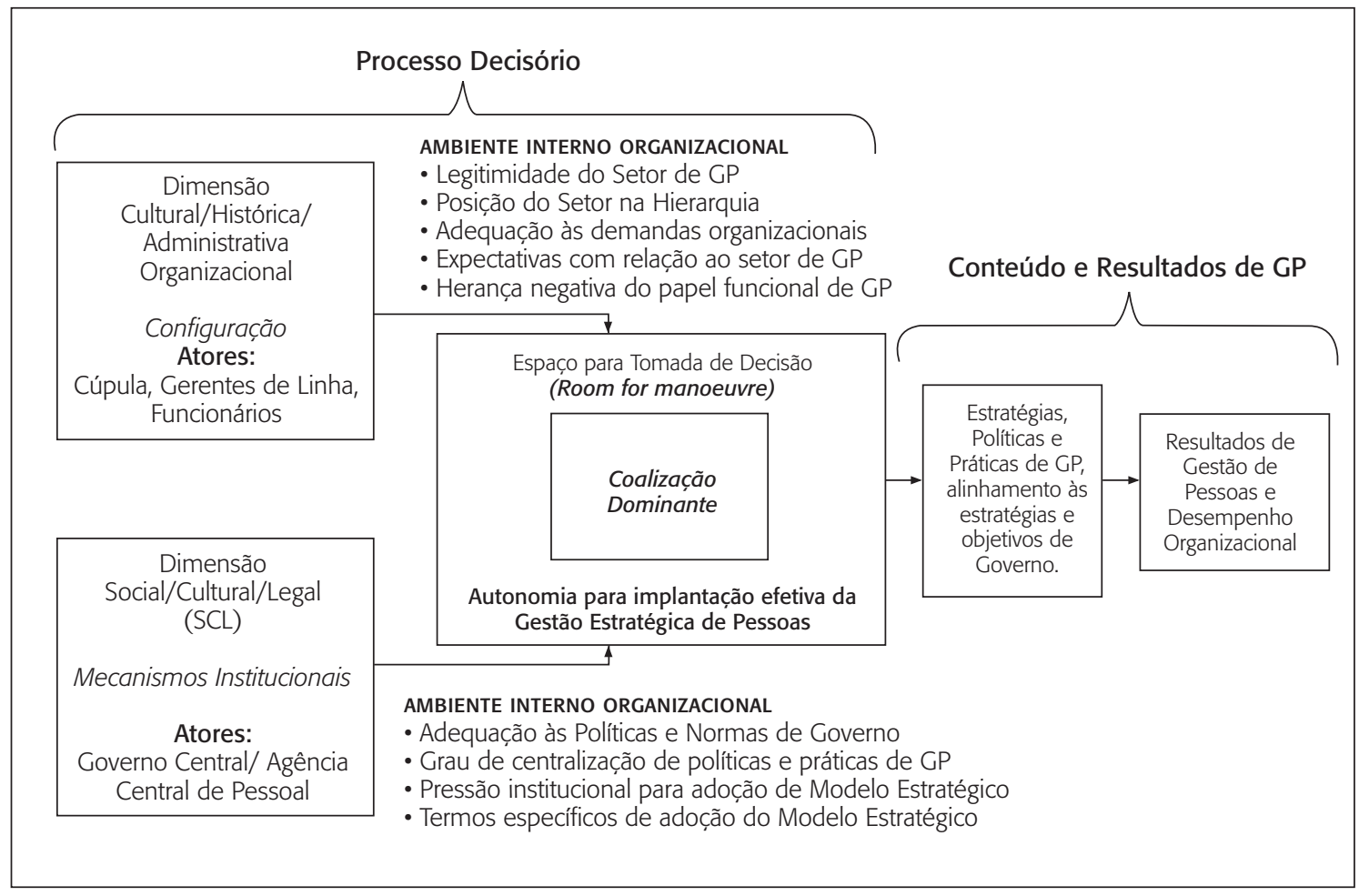

Fonte: Elaborado com base em Paauwe (2004).

Fatores do ambiente político-institucional, fatores intraorganizacionais e, por fim, características individuais interferem no grau de autonomia que efetivamente influenciará o cotidiano das atividades do setor de GP. Por conseguinte, consoante previsão de modelos estratégicos, os resultados proporcionados pelas práticas de GP contribuem para o desempenho organizacional. Dessa forma, propõe-se o uso da autonomia como medida para identificação da capacidade do setor de GP para adequação de seus processos e práticas, visando à contribuição para a estratégia e objetivos organizacionais. A perspectiva proposta insere a autonomia como uma variável integrante de modelos de GEP, de forma a refletir os aspectos restritivos do ambiente organizacional e permitir sua contextualização, isto é, uma abordagem contingencial para a adequação de modelos teóricos (Horwitz, 1999), os quais têm sido definidos e aplicados, tradicionalmente, de maneira normativa e prescritiva (Legge, 2005).

A identificação do perfil estratégico de gestão de pessoas, conforme a abordagem proposta por Paauwe (2004), se expressa em dois elementos de análise fundamentais: 1) Conteúdo: referente às características e aos resultados dos processos dessa atividade (Truss, 2008; Gratton, 1999; Wright e Snell, 1998), amplamente provida e fundamentada pela literatura 
prescritiva de modelos estratégicos e; 2) Processo: referente à participação do setor de GP no processo decisório organizacional. Essa perspectiva processual é abordada com lacunas na literatura (Paauwe, 2004), porém se busca sua melhor elucidação no presente ensaio teórico mediante a incorporação de teorias referentes à autonomia e à descentralização. De forma convergente com as perspectivas formal-sinóptica e informal-incremental do processo decisório organizacional, a distinção entre autonomia formal e informal viabiliza a caracterização da natureza dos elementos do ambiente organizacional relevantes para a atuação estratégica da unidade de gestão de pessoas. Para tanto, há uma consideração de fatores tanto do ambiente normativo (e.g., legislação, estratégia formal e estrutura) quanto do ambiente político (e.g., relações de poder, influência e legitimidade). Visando subsidiar pesquisas nessa perspectiva, são propostas as seguintes definições constitutivas e operacionais das variáveis que constituem os elementos fundamentais da GEP (Paauwe, 2004).

\section{Objetos de análise da gestão de pessoas da perspectiva do conteúdo das atividades e autonomia para tomada de decisão}

\begin{tabular}{|c|c|c|c|c|}
\hline \multirow{3}{*}{$\begin{array}{l}\text { Elementos } \\
\text { de Análise }\end{array}$} & \multirow{2}{*}{ Conteúdo } & \multicolumn{3}{|c|}{ Processo Decisório } \\
\hline & & \multicolumn{2}{|c|}{ Formal-Sinóptico } & Informal-Incremental \\
\hline & $\begin{array}{l}\text { Políticas e Práticas de } \\
\text { Gestão de Pessoas }\end{array}$ & $\begin{array}{l}\text { Descentralização } \\
\text { Governamental }\end{array}$ & Autonomia Formal & Autonomia Informal \\
\hline $\begin{array}{l}\text { Definição } \\
\text { Constitutiva }\end{array}$ & $\begin{array}{l}\text { Políticas e práticas que } \\
\text { ocorrem de maneira } \\
\text { sistemática e que } \\
\text { sejam procedimentos } \\
\text { reais e não apenas } \\
\text { retóricos. }\end{array}$ & $\begin{array}{l}\text { Transferência de } \\
\text { poder de uma } \\
\text { organização central } \\
\text { para organizações } \\
\text { subsidiárias. }\end{array}$ & $\begin{array}{l}\text { Extensão da autoridade } \\
\text { para tomada de decisão de } \\
\text { determinado agente. }\end{array}$ & $\begin{array}{l}\text { Capacidade de tomar } \\
\text { decisões sobre atividades } \\
\text { sem interferências de outros } \\
\text { atores. }\end{array}$ \\
\hline $\begin{array}{l}\text { Definição } \\
\text { Operacional }\end{array}$ & $\begin{array}{l}\text { Processos de trabalho } \\
\text { formais e estruturados } \\
\text { que expressem as } \\
\text { rotinas executadas de } \\
\text { trabalho e funções do } \\
\text { setor de gestão de } \\
\text { pessoas. }\end{array}$ & $\begin{array}{l}\text { Quantidade de } \\
\text { decisões discricionárias } \\
\text { relativas aos processos } \\
\text { e às atividades de } \\
\text { gestão de pessoas da } \\
\text { organização. }\end{array}$ & $\begin{array}{l}\text { Existência de normativos } \\
\text { ou práticas formais que } \\
\text { concedam autoridade } \\
\text { decisória em caráter } \\
\text { final nos processos de } \\
\text { gestão de pessoas para o } \\
\text { respectivo setor. }\end{array}$ & $\begin{array}{l}\text { Percepção dos gestores e } \\
\text { servidores sobre a influência } \\
\text { do setor de gestão de } \\
\text { pessoas sobre os próprios } \\
\text { processos e resultados em } \\
\text { relação a atores internos e } \\
\text { externos à organização. }\end{array}$ \\
\hline $\begin{array}{l}\text { Fatores } \\
\text { Analisados }\end{array}$ & $\begin{array}{l}\text { Configuração e perfil } \\
\text { das atividades de } \\
\text { gestão de pessoas; } \\
\text { vinculação estratégica. }\end{array}$ & $\begin{array}{l}\text { Legislação relativa } \\
\text { ao tema, políticas } \\
\text { de governo, } \\
\text { formas de controle } \\
\text { governamental. }\end{array}$ & $\begin{array}{l}\text { Estrutura, hierarquia, } \\
\text { normas e regulamentos } \\
\text { organizacionais, } \\
\text { participação formal em } \\
\text { reuniões estratégicas. }\end{array}$ & $\begin{array}{l}\text { Legitimidade e inserção em } \\
\text { decisões organizacionais } \\
\text { de gestão de pessoas, } \\
\text { interferências políticas e } \\
\text { administrativas, formas de } \\
\text { atuação de atores políticos e } \\
\text { agências de controle. }\end{array}$ \\
\hline
\end{tabular}

Fonte: Elaboração própria. 
Os diferentes objetos constituintes do processo de formação da autonomia concorrem por definir a percepção de autonomia real dos atores organizacionais e evidenciar em que medida cada categoria de fatores ambientais (institucionais, organizacionais, formais e informais) é determinante para a implantação efetiva da GEP. Subsidiariamente, características individuais dos principais tomadores de decisão em gestão de pessoas são levadas em consideração, como forma de controle de possíveis influências dessas em suas percepções.

A perspectiva proposta de análise da autonomia de unidades de gestão de pessoas estabelece uma interface entre as literaturas de administração pública e gestão de pessoas que permite avanços em ambos os campos. O avanço em direção a uma abordagem contingencial de gestão de pessoas para o setor público termina por proporcionar o aprofundamento de uma dimensão relevante da autonomia gerencial de organizações públicas.

A consideração de diferentes níveis de análise, macro e meso-organizacional, define, com maior clareza, quais fatores dependem da ação governamental, por meio de normas e políticas gerais, e quais dependem das políticas e arranjos organizacionais e da atuação de gestores públicos. Tal análise mais ampla constitui-se em um avanço ainda a ser aprofundado no contexto brasileiro. Porém, a definição de fatores intervenientes especificamente no nível meso-organizacional constitui-se em uma lacuna na literatura de autonomia no setor público, na medida em que não é descrito, com maior profundidade, como os fatores do ambiente interno e como diferentes perfis de unidades de gestão de pessoas interferem na autonomia gerencial de organizações públicas e, consequentemente, na sua autonomia e desempenho na execução de políticas públicas. Tendo em vista tal perspectiva, são citadas possíveis linhas de pesquisa para o tema e os estudos e teorias que podem servir-lhes de referência.

\section{Agenda de pesquisa proposta}

Como agenda de pesquisa, propõe-se inicialmente o estabelecimento de um lastro teórico para o construto da autonomia com relação à sua dimensionalidade e formas de mensuração, adequadas ao contexto brasileiro. A autonomia é um construto multidimensional (Brock, 2003; Verhoest et al., 2004; Young e Tavares, 2004), cuja mensuração tem ocorrido de maneira heterogênea na literatura, prejudicando a comparação de resultados. No setor público, parte da literatura tem utilizado a abordagem de Verhoest e colaboradores (2004), apresentada neste ensaio, em que seis dimensões de autonomia são propostas. Em tal perspectiva, pesquisas em 30 diferentes países (Verhoest et al., 2011) têm permitido a análise comparativa da autonomia em organizações públicas em diferentes contextos.

Conquanto as dimensões propostas sirvam como referência, a mensuração dos fatores associados a cada dimensão é específica de cada contexto, tendo em vista a diferença entre os mecanismos de controle da administração pública em cada país. Mesmo com a possibilidade de mensuração perceptual da autonomia real de unidades de gestão de pessoas, esta precisa ser corroborada por medidas objetivas dos fatores constituintes de suas dimensões específicas, que concorrem por determinar tais percepções. Apenas dessa forma se possibilita a compreen- 
são da dinâmica da autonomia e a relação entre suas dimensões, a explicação da sua variação entre as organizações e, por fim, se subsidia a intervenção governamental e gerencial sobre os fatores detectados como relevantes. Com base em tais lacunas e nos objetos de análise destacados no presente ensaio, são propostas as seguintes linhas de investigação como agenda de pesquisa:

1) Descentralização: investigar elementos do ambiente institucional, destacadamente o grau de descentralização de políticas de gestão de pessoas no setor público federal, e em que medida restringem a flexibilidade de diferentes atividades como recrutamento, movimentação, desenvolvimento, avaliação e remuneração, tendo em vista o alinhamento horizontal previsto em modelos estratégicos.

2) Autonomia Formal: investigar quais elementos formais da organização, como natureza jurídica, setor de atuação e estrutura, assim como da unidade de GP, como posição hierárquica e inserção no planejamento estratégico, influenciam sua autonomia.

3) Autonomia Informal: investigar quais elementos informais constituem interferências sobre as decisões de unidades de gestão de pessoas e quais estratégias informais são utilizadas por estas para obtenção de maior inserção nas arenas decisórias da organização (Brewster, Larsen e Mayrhofer, 2000). A abordagem de tais aspectos é uma lacuna relevante na literatura de autonomia e gestão de pessoas no setor público, no qual os ambientes políticos, institucional (Ingraham e Rubaii-Barrett, 2007) e organizacional (Drory e Vigoda-Gadot, 2010) desempenham papel relevante. A concepção do papel da atividade de gestão de pessoas, possuída por atores do contexto institucional e organizacional, e a consequente postura de apoio ou resistência a inovações são fundamentais para a institucionalização da GEP no setor público. A realização incompleta das reformas gerenciais no Brasil na década de 1990, por exemplo, principalmente no que se refere à gestão de pessoas, se deveu, em boa medida, pela resistência e ausência de apoio de variados grupos de interesse (BresserPereira, 1998). Fonseca (2013), por sua vez, identifica no âmbito organizacional que o apoio informal da cúpula, gestores e servidores à unidade de gestão de pessoas fornece as bases para obtenção de legitimidade e autonomia para que a unidade seja capaz de propor e operar uma transição para uma abordagem estratégica de GP.

4) Configuração e atuação da unidade de GP: a autonomia se expressa com base na efetividade de competências técnicas e políticas da unidade de gestão de pessoas (Fonseca, 2013). Sob o ponto de vista técnico, devem ser avaliadas, a princípio, as características das atividades de GP e seu grau de alinhamento vertical e horizontal, mas também o acesso a recursos tecnológicos, financeiros e a uma força de trabalho adequada, por exemplo (Paauwe, 2004). Sob o ponto de vista político, é relevante a análise do perfil do gestor e funcionários de GP e sua atuação na organização, uma vez que, no setor público, as mudanças pretendidas na atividade de GP aparentemente não foram acompanhadas de uma mudança na postura dos gestores e funcionários, os quais devem buscar maior inserção no processo decisório organizacional (Ingraham e Rubaii-Barrett, 2007). 
5) Relação da autonomia em GP com variáveis da força de trabalho e organizacionais: a relação com variáveis da força de trabalho pode ser investigada para análise de possíveis efeitos da autonomia nos resultados de práticas de gestão de pessoas (Paauwe, 2004), a exemplo do grau de qualificação, taxas de turn-over, motivação e satisfação da força de trabalho. Finalmente, a integração de variáveis de desempenho organizacional na análise termina por definir um modelo teórico-empírico completo de GEP, nos termos propostos por Paauwe (2004).

Em cada uma das linhas de pesquisa proposta, a autonomia real percebida por integrantes de unidades de GP serve de referência para identificação de fatores ambientais e definição de como esses se relacionam com a capacidade da unidade de adequar seus processos para atendimento dos objetivos organizacionais, cumprindo seu papel estratégico. Menciona-se na literatura uma falta de clareza acerca das relações de causalidade entre a autonomia e seus fatores, dado o seu aspecto recursivo (Young e Tavares, 2004). Pesquisas nesse sentido podem elucidar quais fatores se constituem efetivamente em antecedentes e consequentes da maior autonomia em GP. Finalmente, cabe ressaltar que não se descartam as possíveis interfaces com a literatura correlata, e relativamente mais consolidada, de autonomia no contexto de multinacionais (Young e Tavares, 2004, para uma revisão desse campo) com estudos acerca das motivações que ensejam a criação de sistemas mais centralizados ou descentralizados de GP, sua relação com o ambiente institucional e estratégias organizacionais, implicações para as práticas adotadas em subsidiárias e efeitos em seu desempenho (e.g., Muritiba et al., 2010; Farndale et al., 2010; Ferner et al., 2004). Tais questões convergem com lacunas teóricas e empíricas da implantação da GEP no setor público e podem subsidiar teórica e metodologicamente pesquisas nesse campo.

A agenda de pesquisa proposta permite a abrangência da complexidade do ambiente do setor público federal brasileiro para melhor compreensão das limitações e dos desafios que governo e organizações públicas devem transpor para a almejada implantação de modelos estratégicos de GP. Os fatores investigados podem se constituir em potenciais indicadores para monitoramento e intervenção dos atores políticos e organizacionais que visem promover a gestão estratégica de pessoas. As pesquisas fornecem melhor perspectiva para comparação do contexto nacional àquele de outros países e definir, de fato, quais modelos podem servir de referência em razão da maior similaridade de fatores culturais e institucionais.

Sob um ponto de vista teórico, a reunião de estudos relacionados à agenda de pesquisa proposta, na medida em que possuem uma base teórica comum, pode ser gradualmente consolidada em uma teoria contextualmente fundamentada de gestão de pessoas para o setor público federal brasileiro. Teorias contextualmente fundamentadas prescrevem modelos empíricos, porém preveem a adaptação de construtos, relações e variáveis a cada ambiente específico, concedendo-lhes maior poder explicativo e de identificação de quais aspectos teóricos são comuns e transversais e quais são relativos, implicando diferentes aplicações da teoria em cada contexto. 


\section{Considerações finais}

O presente ensaio teórico teve como objetivo a proposição da variável autonomia como construto integrante de modelos estratégicos de gestão de pessoas adaptados ao setor público federal. As teorias tradicionais de gestão estratégica possuem como pressuposto a capacidade de adequação de políticas e práticas de GP à estratégia organizacional. Essa perspectiva pode não corresponder à prática de organizações marcadas pela inserção em um ambiente normativo mais restritivo e pela influência de múltiplos stakeholders, tais como as organizações públicas federais (Ingraham e Rubaii-Barrett, 2007; Paauwe, 2004; Paauwe e Boon, 2009). Nesse sentido, a operacionalização do conceito de autonomia verifica a relação dessa variável com as condições para a implantação do modelo estratégico no setor público federal.

As definições operacionais utilizadas neste ensaio podem servir de base para a análise do papel da autonomia em diferentes atividades, além da gestão de pessoas. Posto de lado o aspecto valorativo e ideológico que permeou o conceito de autonomia sob o ideário do NPM (Smullen, 2003), esta se constitui em uma variável central para a organização do Estado. Toda a estrutura normativa e gerencial da administração pública embute a concepção de legisladores e agentes políticos de determinados níveis de autonomia, julgados adequados para a coordenação e a efetividade de políticas públicas. O estudo da autonomia e de seus efeitos, principalmente em políticas de gestão, ainda possui uma literatura incipiente com relação à definição, mensuração e relações dos seus construtos. No atual cenário, permeado de desafios com respeito aos novos papéis, limites e funções do Estado, a administração pública em alguns pontos tem se fundamentado mais em ideologias e modismos gerenciais do que em sólidas bases teóricas. Nesse sentido, uma teoria consolidada, que permita a análise das estruturas reais de poder na administração pública e possa relacionar tais processos à sua maior efetividade, é uma lacuna fundamental. Com a criação de uma base teórica adaptada ao contexto nacional, o aperfeiçoamento da administração pública brasileira pode ocorrer de forma progressiva, amparado por uma base própria de conhecimentos científicos, deixando de se basear em impressões subjetivas que variem conforme as mudanças de gestão ou, ainda, em transposições inadequadas de modelos estrangeiros.

\section{Referências}

APPEL, Heitor; BITENCOURT, Claudia C. Gestão de pessoas por competência: institucionalização, possibilidades e dificuldades implícitas nas relações trabalhistas brasileiras. Revista O\&S, Salvador, v. 15, n. 46, p. 175-193, jul./set. 2008.

BACH, Stephen. Human resource management in public sector. In: WILKINSON, Adrian et al. The sage handbook of human resource management. Londres: Sage Publications, 2010.

BRAADBAART, Okke; VAN EYBERGEN, Niels; HOFFER, Jan. Managerial autonomy: does it matter for the performance of water utilities? Public Administration and Development, v. 27, n. 2, p. 111-121, 2007. 
BRANDÃO, Hugo P.; BAHRY, Carla P. Gestão por competências: métodos e técnicas para mapeamento de competências. Revista do Serviço Público - RSP, Brasília, v. 56, n. 2, p. 179-194, abr./jun. 2005.

BRANDÃO, Hugo P.; GUIMARÃES, Tomás de A. Gestão por competências e gestão de desempenho: tecnologias distintas ou instrumentos de um mesmo constructo? Revista de Administração de Empresas - RAE, São Paulo, v. 41, n. 1, p. 8-15, jan./mar. 2001.

BRANDL, Julia; POHLER, Dionne. The human resource department's role and conditions that affect its development: explanations from Austrian CEOs. Human Resource Management, v. 49, n. 6, p. 1025-1046, nov./dez. 2010.

BRASIL. Constituição (1988). Constituição da República Federativa do Brasil. Brasília, DF: Senado, 1998.

BRASIL. Decreto n. 5.378, de 23 de fevereiro de 2005. Institui o Programa Nacional de Gestão Pública e Desburocratização - Gespública e o comitê gestor do Programa Nacional de Gestão Pública e Desburocratização, e dá outras providências. Presidência da República, Brasília, 2005.

BRASIL. Decreto n. 5.707, de 23 de fevereiro de 2006. Institui a política e as diretrizes para o desenvolvimento de pessoal da administração pública federal direta, autárquica e fundacional, e regulamenta dispositivos da Lei no 8.112, de 11 de dezembro de 1990. Presidência da República, Brasília, 2006.

BRESSER-PEREIRA, Luiz C. Da administração pública burocrática à gerencial. Revista do Serviço Público - RSP, Brasília, v. 49, n. 1, p. 5-42, jan./mar. 1998.

BREWSTER, Chris; LARSEN, Henrik H.; MAYRHOFER, Wolfgang. Human resource management: a strategic approach? In: BREWSTER, Chris; LARSEN, Henrik H. Human resource management in Northern Europe: trends, dilemmas and strategy. Oxford: Blackwell Publishers, 2000. p. 39-65.

BROCK, David M. Autonomy of individuals and organizations: towards a strategy research agenda. International Journal of Business and Economics, v. 2, n. 1, p. 57-73, 2003.

DATTA, Depak K.; GUTHRIE, James P.; WRIGHT, Patrick M. Human resource management and labor productivity: does industry matter? Academy of Management Journal, v. 48, n. 1, p. 135-145, 2005.

DE PABLOS, Patricia O. Human resource management systems and their role in the development of strategic resources: empirical evidence. Journal of European Industrial Training, v. 28, n. 6, p. 474-489, 2004.

DRORY, Amos; VIGODA-GADOT, Eran. Organizational politics and human resource management: a typology and the Israeli experience. Human Resource Management Review, v. 20, n. 3, p. 194-202, 2010.

FARNDALE, Elaine et al. Context-bound configurations of corporate HR functions in multinational corporations. Human Resource Management, v. 49, n. 1, p. 45-66, jan./fev. 2010. 
FERNER, Anthony et al. The dynamics of central control and subsidiary autonomy in the management of human resources: case-study evidence from US MNCs in the UK. Organization Studies, v. 25, n. 3, p. 363-391, 2004.

FERRIS, Gerald R. et al. Human resources reputation and effectiveness. Human Resource Management Review, v. 17, n. 2, p. 117-130, 2007.

FONSECA, Diogo R. da. Autonomia de unidades de gestão de pessoas para desempenho das atividades estratégicas de capacitação na administração pública federal. Dissertação (mestrado) — Programa de Pós-Graduação em Administração, Universidade de Brasília, Brasília, 2013.

GARAVAN, Thomas N.; COSTINE, Pat; HERATY, Noreen. The emergence of strategic human resource development, Journal of European Industrial Training, v. 19, n. 10, p. 4-10, out. 1995.

GOODERHAM, Paul N.; NORDHAUG, Odd; RINGDAL, Kristen. Institutional and rational determinants of organizational practices: human resource management in European firms. Administrative Science Quarterly, v. 44, n. 3, p. 507-531, set. 1999.

GRATTON, Lynda. People process as a source of competitive advantage. In: GRATTON, Lynda et al. Strategic human resource management: corporate rethoric and human reality. Oxford: University Press, 1999. p. 170-198.

HORTON, Sylvia. Introduction - the competency movement: its origins and impact on the public sector. The International Journal of Public Sector Management, v. 13 n. 4, p. 306-318, 2000.

HORWITZ, Frank M. The emergence of strategic training and development: the current state of play. Journal of European Industrial Training, v. 23, n. 4-5, p. 180-190, 1999.

HOU, Yilin et al. Decentralization of human resource management: driving forces and implications. Review of Public Personnel Administration, v. 20, n. 4, p. 9-22, out. 2000.

INGRAHAM, Patricia W.; RUBAII-BARRETT, Nadia. Human resource management as a core dimension of public administration. Foundations of Public Administration Series, Public Administration Review Website, 2007.

LACOMBE, Beatriz M. B.; TONELLI, Maria J. O Discurso e a prática: o que nos dizem os especialistas e o que nos mostram as práticas das empresas sobre os modelos de gestão de recursos humanos, Rev. Adm. Contemp., Curitiba, v. 5, n. 2, p. 157-174, maio/ago. 2001.

LEGGE, Karen. Human resource management: rhetorics and realities; Anniversary Edition. Londres: Macmillan Business, 2005.

MCCRACKEN, Martin; WALLACE, Mary. Exploring strategic maturity in HRD: rhetoric, aspiration or reality? Journal of European Industrial Training, v. 24, n. 8, p. 425-467, 2000.

MULLER, Michael. Human resource management under institutional constraints: the case of Germany. British Journal of Management, v. 10, n. s1, p. 31-44, 1999.

MURITIBA, Patricia M. et al. International HR strategy in Brazilian technology multinationals. BAR, Braz. Adm. Rev., Curitiba, v. 7, n. 4, p. 325-344, out./dez. 2010. 
OCDE. Organização para Cooperação e Desenvolvimento Econômico. Avaliação da gestão de recursos humanos no governo - relatório da OCDE: Brasil, Governo Federal (Portuguese version). Paris: OECD Publishing, 2010a.

OCDE. Organização para Cooperação e Desenvolvimento Econômico. Managing competencies in government: state of the art practices and issues at stake for the future. Paris: OECD Publishing, 2010b.

PAAUWE, Jaap. HRM and performance: achieving long term viability. Oxford: Oxford University Press, 2004.

PAAUWE, Jaap; BOON, Corine. Strategic HRM: a critical review. In: COLLINGS, David G.; WOOD, Geoffrey (Ed.). Human resource management: a critical approach. Nova York: Routledge, 2009. p. 38-54.

PACHECO, Regina S. Política de recursos humanos para a reforma gerencial: realizações do período 1995-2002. Revista do Serviço Público - RSP, v. 53, n. 4, p. 79-106, 2002.

PECI, Alketa; PIERANTI, Octavio P.; RODRIGUES, Silvia. Governança e New Public Management: convergências e contradições no contexto brasileiro. Revista O\&S, v. 15, n. 46, p. 39-55, jul./set. 2008.

PETERS, Brainard Guy. Os dois futuros do ato de governar: processos de descentralização e recentralização no ato de governar. Revista do Serviço Público - RSP, Brasília, v. 59, n. 3, p. 289-207, jul./set. 2008.

SHEEHAN, Cathy. A model for HRM strategic integration. Personnel Review, v. 34, n. 2, p. 192-209, 2005.

SMULLEN, Amanda. Autonomia, liberdade e independência: a evolução de uma família de conceitos e seu advento à arena da administração pública. Rev. Adm. Pública, Rio de Janeiro, v. 37, n. 3, p. 551-568, maio/jun. 2003.

TORRACO, Richard J.; SWANSON, Richard A. The strategic roles of human resource development. Human Resource Planning, v. 18, n. 4, p. 10-22, dez. 1995.

TRUSS, Catherine. Continuity and change: the role of the HR function in the modern public sector. Public Administration, v. 84, n. 4, p. 1071-1088, 2008.

TRUSS, Catherine. Strategic HRM: enablers and constraints in the NHS. The International Journal of Public Sector Management, v. 16, n. 1, p. 48-60, 2003.

VERHOEST, Koen et al. Governing public agencies in the 21st Century: international lessons and policy recommendations by the COST Action IS0601 on comparative research into current trends in public sector organization - CRIPO/COBRA, COST Office, 2011.

VERHOEST, Koen et al. The study of organizational autonomy: a conceptual review. Public Administration Development, v. 24, n. 2, p. 101-118, 2004.

VIEIRA, Paulo R. Em busca de uma teoria de descentralização. Rev. Adm. Pública, Rio de Janeiro, v. 46, n. 5, p. 1409-1425, set./out. 2012. 
WOOD JR, Thomaz; TONELLI, Maria J.; COOKE, Bill. Colonização e neocolonização da gestão de recursos humanos no Brasil (1950-2010). Rev. Adm. Empres., São Paulo, v. 51, n. 3, p. 232-243, jun. 2011.

WRIGHT, Patrick M.; SNELL, Scott A. Toward a unifying framework for exploring fit and flexibility in strategic human resource management. Academy of Management Review, v. 23, n. 4, p. 756-772, 1998.

YESILKAGIT, Kutsal; VAN THIEL, Sandra. Political influence and bureaucratic autonomy. Public Organization Review, v. 8, n. 2, p. 137-153, 2008.

YOUNG, Stephen; TAVARES, Ana. T. Centralization and autonomy: back to the future. International Business Review, v. 13, n. 2, p. 215-237, abr. 2004.

Diogo Ribeiro da Fonseca é mestre em administração pelo Programa de Pós-Graduação em Administração da Universidade de Brasília (UnB) e técnico administrativo na Coordenação-Geral de Pesquisa da Escola Nacional de Administração Pública (ENAP). E-mail: diogorfonseca@gmail.com.

Pedro Paulo Murce Meneses é professor adjunto do Departamento de Administração e pesquisador credenciado do Programa de Pós-Graduação em Administração da Universidade de Brasília (UnB), onde desenvolve pesquisas sobre políticas de gestão de pessoas na administração pública. E-mail: pemeneses@ yahoo.com.br.

Antônio Isidro da Silva Filho é doutor em administração pela Universidade de Brasília (UnB), professor adjunto do Departamento de Administração e do Programa de Pós-Graduação em Administração da UnB. E-mail: isidro@unb.br.

Natália Gomes Campos é mestranda no Programa de Pós-Graduação em Administração da Universidade de Brasília (UnB) e técnica administrativa na Agência Nacional de Transportes Terrestres (ANTT). Email: natygomes6@gmail.com. 
